\title{
AC 2008-425: PROGRESSIVE RESEARCH ON A WIRELESS AUTOMATED HIGHWAY SYSTEM: THE AUTONET SUPERPROJECT
}

\section{Johnny Chang, National University}

Johnny Chang received a Bachelor of Science degree in Economics Management with a minor in Political Science from University of California, San Diego (UCSD) in 2005. He received a Master of Science in Wireless Communications from National University, San Diego in 2007. He is currently working as a full-time Systems Engineer with the Accenture National Security Services (formerly Maxim Systems) in San Diego, where he is gaining valuable experience and professionalism in satellite wireless communications and GPS.

\section{Ayman EI Salim, National University}

Ayman El Salim received a Master of Science in Wireless Communications from National University, San Diego in 2007. Since completing an engineering internship with Qualcomm Inc., San Diego, he is working as a Software System Test Engineer with Sierra Wireless in San Diego, CA.

\section{Ronald Uhlig, National University}

Dr. Ronald P. Uhlig is Chair of the Department of Computer Science and Information Systems, School of Engineering and Technology, National University. He also serves as Lead Faculty for Wireless Communications for the Master of Science in Wireless Communications program. He teaches and carries out research in wireless systems, computer security, and applications of advanced technology in education. He also teaches global business.

As Principal Investigator for a Hewlett-Packard Technology for Teaching - Higher Education Grant received from HP, he is conducting research into the effectiveness of advanced technology in teaching complex information structures. He is a member of the Steering Committee for Project Inkwell (www.projectinkwell.com).

Prior to joining the National University faculty, he was President/CEO, SegWave, Inc., an educational technology systems company he founded in 2000.

He was Vice President for Russia and Eastern Europe, Qualcomm Inc., 1995-99, with offices in San Diego and Moscow. He was with Northern Telecom, 1984-95 in multiple positions including Director, Intelligent Network Solutions and Director, Asia/Pacific Strategic Marketing. He was with Bell-Northern Research, Ottawa, Canada, 1978-1984. He had nationwide responsibility for US Army Materiel Command scientific \& engineering computing, 1969-78, introducing many applications in what has become today's Internet. He served as a US Army Officer in the Office of the Chief of Staff, in the Pentagon, 1966-1968.

He was Chairman, IFIP TC-6 (International Federation for Information Processing Technical Committee on Data Communications) 1985-91. He founded and from 1979-1985 he chaired WG 6.5, the Working Group on Electronic Messaging of IFIP TC-6, and is one of the "fathers" of email. He was President, International Council for Computer Communication (ICCC), 1992-96.

$\mathrm{He}$ is an elected Academician of the International Telecommunications Academy, and was awarded the Academy's Gold Medal in 2000 for sustained contributions to tele-communications. He was Program Chairman, World Computer Congress, Hamburg, Germany, 1994.

With co-authors David J. Farber and James Bair, he was lead author of the first book on Office Automation, The Office of the Future, North-Holland, Amsterdam, 1979 and he published the first popular paper on email (Datamation, 1977).

He holds a B.Sc. in Physics from the Massachusetts Institute of Technology, and a Ph.D. in Physics from the University of Maryland. 


\section{Michelle Bright, National University}

Dr. Michelle M. Bright is an Assistant Professor at National University in the School of Engineering and Technology. For 18 years, Michelle was a senior research engineer at NASA Glenn Research Center based in Cleveland, Ohio. Her research focused on aero-engine controls and diagnostics, specifically for the detection and control of rotating stall and surge in compressors, and the design of micro-flow control device technology. Dr. Bright is now a full time faculty for the Wireless Communications Master's degree program. Michelle's experience in Matlab/Simulink programming for real-time systems has allowed her to develop new laboratory based curriculum for the wireless program. She brings extensive knowledge of signal processing, device architecture, hardware design, and autonomous controls to her research. She is co-author of a NASA grant for encryption using nonlinear signal processing techniques. She is a recipient of numerous Air Force and DARPA funded research grants for flow control. Prior to joining the National University faculty, Dr. Bright has authored over 30 publications and journal articles, been an invited lecturer, and served as an ASME/IGTI reviewer and session chair. She has received the NASA Wings of Excellence Award, the NASA Best Publication Award, the NASA Medal of Honor for scientific excellence, and 2 ASME/IGTI Best Paper Awards (1 from the Turbomachinery Committee and 1 from the Controls and Diagnostics Committee). Michelle holds a BS EE and BS BME from Carnegie-Mellon University, an MSEE from University of Texas at Arlington, and a PhD EE from the University of Akron in Ohio. 


\title{
Progressive Research On A Wireless Automated Highway System: The AutoNet SuperProject
}

\begin{abstract}
A Master's Research Project, the culmination of the Master of Science in Wireless

Communications (MSWC) degree at National University, is normally completed within three to four months. This paper discusses National University's experience with an approach in which research on various aspects of topics too complex to be completed within three months is to be passed to successive groups of students.
\end{abstract}

The initial project chosen for this approach is the AutoNet Progressive Research Project. "AutoNet" is a next-generation automobile traffic wireless network system for future "smart cars" that can both communicate with each other wirelessly, and be operated automatically on super highways. Due to cost and time constraints, the initial project had to be confined to a "light" version of the concept. A simplified demonstration was developed, using Bluetooth, GPS, and RF transmitters and receivers with specially equipped, remotely-controlled cars, to compute instantaneous distance between the cars and notify the operators of impending collisions.

This low-cost demonstration system sent GPS information through a Bluetooth-enabled GPS receiver from the remotely-controlled cars to a laptop computer that simulated a wireless base station. MATLAB software running on the laptop combined the two GPS data streams, and then computed when a collision was likely. Finally, the laptop sent a signal via an RF transmitter to receivers mounted in the cars to alert the drivers to a possible collision before the cars got too close to each other. The relative positions of the two cars were also displayed on a visualization map.

The demonstration system proved to be a powerful tool for students to integrate what they had learned across the MSWC program, but it had to leave many important areas of research untouched due to time limitations. The students and faculty mentors then identified key "next research" areas so that the project could be passed on to successive groups of students scheduled to complete their Master's Research Projects at a later time. Each new group is responsible for choosing which of the next areas of research interest them the most, so they can carve out a project that will enable them to both demonstrate mastery of wireless communications principles and practice, and consecutively, carry out real research on meaningful topics. By integrating each new set of results with prior results, and recommending what should be done next, students are better prepared for the real world where they will work in teams to build on each other's work to produce high quality results.

\section{Introduction}

Master's Degree programs in the National University School of Engineering and Technology culminate in a Research Project in which teams of 2-4 students normally spend three months to complete an in-depth research project that demonstrates their mastery of all that they have learned in the program. The majority of the first month is spent developing a detailed project plan. They conduct most of their research in the second month, and then spend much of the final month documenting their work. They must complete two tasks: 1) write a 15,000 to 40,000 word report which displays both technical depth and breadth and 2) defend their research results 
in an oral presentation to a panel of experts. The panel includes both faculty and industry experts.

One or two months to actually conduct the research phase of the project can limit the topics that students can address. One of the fastest growing programs in National University is the Master of Science in Wireless Communications. During the last year, enrollment in this program has increased by a factor of six from approximately 12 students to nearly 75 students at the time this paper was written. After learning the fundamentals of radio-based communications systems, students are taught about many areas of research that are on-going in this fast growing field, and some of the possible applications of wireless communications. It is as this point that students are given three months to choose a topic and complete their research.

In the past, their choices have been limited. Some of the most interesting potential research projects would require integration of several different wireless communication technologies. To do a thorough job on such projects would require one or two years, rather than the three months allotted for the Master's Research Projects. Nevertheless, a number of students have wanted to work on such larger projects.

As has been noted in the Engineer of 2020 report $^{1}$, the most significant engineering work in the future will be done by teams rather than by individuals. In keeping with this, National University is exploring the concept of working with students to identify larger projects, but then carving up the research into multiple areas that are suitable for three month projects, and then allow students to pick one of those areas for their own projects. It is possible that a few teams might work simultaneously on different aspects of the same overall project. But, it is more likely that the work will be done in different Master's Research Project classes, taught by different instructors at different times.

At the writing of this paper there are five different cohorts of students currently working on the Master of Science in Wireless Communications (MSWC) degree, and four of the five cohorts will work on their research projects at different times. Students have proven to be reasonably adept at identifying interesting projects. But they have proved to be less adept at assessing how much time will be required to complete the research for their project despite the fact that they are required to develop a detailed project plan using Microsoft Project. Overestimating how much work they can complete in three months is common. It is the responsibility of the instructor for a Master's Research Project class to work with students to reduce the scope of their projects to something that can be completed successfully within the allotted 3-month period. It is during this process that the potential emerges for other groups of students to work on closely related projects. Once such potential is identified, it becomes the job of the faculty to integrate the work of different teams, conducted at varying times, into a "whole" that moves the overall project forward. We are calling this approach to Master's Research Projects "Progressive Research".

\section{First NU Progressive Project - An Automated Highway System}

National University's first project chosen to explore this progressive research approach was not originally conceived as a progressive project. Two of the authors, who are graduates of the National University Master of Science in Wireless Communication program, developed an intense interest in research on the "automated highway", however, it quickly became apparent that only the rudiments of the concept could be demonstrated in the available time for their threemonth Master's Research Project. Their interest continued after they graduated, and this 
became the driving force for the first "progressive project." The remainder of this section describes the research they completed for their Master's Research Project.

Ever since motor vehicles were invented, people have dreamed of having automobiles that are "smart" enough to operate themselves, instead of having to be driven. As the world of wireless communications continues to expand exponentially, mobile communication devices which used to be just a dream are now widely available. Supported data transmission rates, mobile processing power and the range of wireless coverage continues to expand dramatically. The point has been reached where today's technology has the potential to realize the dream. A significant component will be based on wireless communications networking between vehicles.

Extensive past work has been done on the concept. Though the National Highway System Research Consortium terminated their work in the late 1990s, their project report stated that the "review should not be construed as critical of further efforts to undertake research on vehicle and highway automation with a long-range and systems perspective." 2 More than a decade has passed since the California PATH project tested a prototype Automated Highway System in San Diego County in 1997. ${ }^{3}$ Given the dramatic developments of the past decade in both wireless technology and computer technology it is appropriate to revisit the subject, and this is starting to happen. This project is similar to work done using Motorola technology in Michigan in $2005 .{ }^{4}$ Other important efforts include the IEEE WAVE (Wireless Access in Vehicular Environments) family of standards that operate in the $5.9 \mathrm{GHz}$ band $^{5,6}$ and the IEEE VANET (Vehicle Ad-Hoc Network) project. ${ }^{7}$

The concept of this project calls for a next generation automobile traffic network system combining the latest wireless communications technologies with a modern traffic network system. By merging existing wireless technologies such as the GPS positioning system ${ }^{8}$, WiMAX $^{9}$ or W-CDMA ${ }^{10}$ cellular network, and obstacle detecting radar sensors, each car can be linked to a network, and interacting with other nearby cars through that network. Each vehicle is equipped with the intelligence to know the exact direction other vehicles are going, and how fast they are driving on highway lanes. The result is an automated automobile system that uses a wireless network on highways to improve traffic efficiency and safety as shown in Figure 1.

The vehicles are only automated by the system when they enter the highway, and human control is still required before entering and after exiting the highway. Immediately before a car enters the highway, the driver stops and waits for network establishment from a base station. At the same time, the driver must enter a destination exit. As soon as the connection is established between the vehicle and the network, other cars on the merging lane are slowed down or told to change lanes to permit the waiting vehicle to enter. When the destination is entered, just before entrance onto the highway, the system calculates the number of exits the vehicle must travel to reach its destination and it determines the best lane of travel for safety and to maximize use of the highway's capacity. A message is then sent to notify the entering vehicle in which lane it is authorized to travel. This approach is intended to optimize the speed of all vehicles on the highway, and has been proven to work by the California PATH project. ${ }^{11}$ Once the vehicles enter the highway, they change lanes only when necessary. Each lane represents a channel and each vehicle represents a node in a network structure. Unless vehicles receive authorization from the network to change lanes, they must travel and remain in the same order. As the car travels on the exit ramp, the driver is notified that the destination exit has been reached. Control is switched back to the driver and the car is disconnected from the network. 


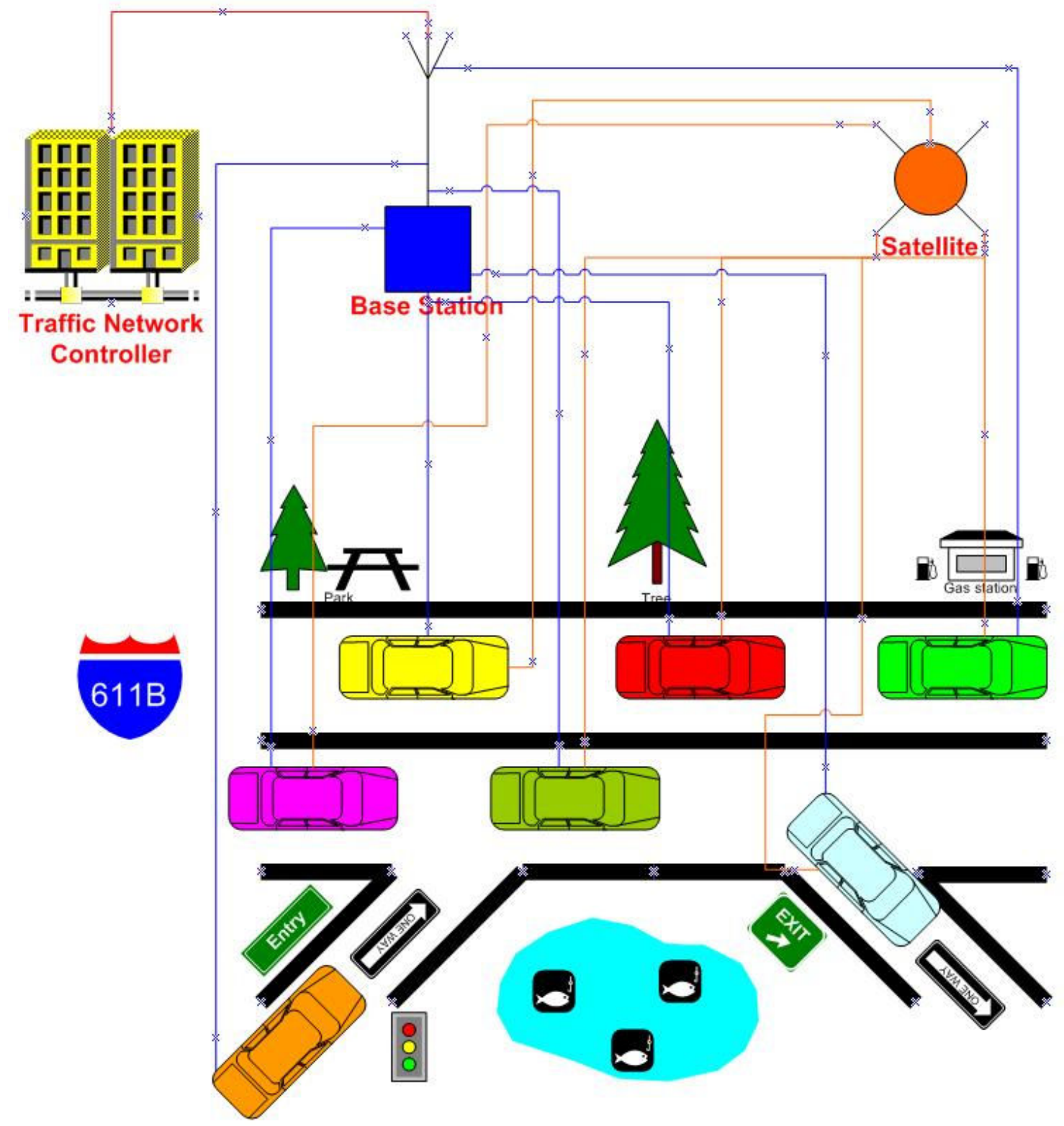

Figure 1: Overview of the Concept

Some of the benefits of this approach include: saving time for commuters by optimizing the speed and traffic throughput and reducing financial losses due to automobile collisions. Most importantly, the network will improve safety as well as quality of life for drivers by reducing the number of accidents and injuries caused by human error. 


\section{Technology Overview of Full Concept}

\section{GPS and Data Collection}

Each vehicle is equipped with a satellite GPS receiver that has the ability to calculate and transmit the position, speed, and direction of the receiver. Every car transmits its current position, speed, and direction wirelessly to a nearby wireless antenna along the highway using a WiMAX or W-CDMA protocol. A single antenna (base station) communicates with all vehicles within its region. Cars communicate using their VIN (Vehicle Identification Number) so packets of information can be easily distinguished. Each base station receives the traffic information from each vehicle; in turn it forwards the collected data to a traffic network controller that collects and processes traffic information for an entire segment of the highway.

\section{Wireless Network, Traffic Network Controller, and Vehicle Controller}

The traffic network controller is the "brain" of the automated highway system and is connected to the base stations through a network of reliable wireless connections (e.g. WiMAX). The traffic network controller requires very fast processors and a large memory to be able to hold and process vehicle information. The traffic network controller continuously calculates each car's vector direction of travel relative to all other vehicles, and identifies any problems. These results are sent back to nearby base stations via the ground network or WiMAX. This information is used in conjunction with obstacle detecting radar to make appropriate course corrections.

\section{Obstacle-Detecting Radar Sensors}

Because GPS is limited in its positioning accuracy, coordinate readings for the same position vary constantly due to dynamic constellation changes of the satellites. To increase the accuracy of the computation of distances between the vehicles, all cars would be equipped with a total of 12 to 16 obstacle-detecting sensors mounted in the front and rear bumpers as well as the sides of the cars. Each of the sensors would transmit $40 \mathrm{kHz}$ ultrasonic waves in wide-angle to detect any nearby obstacles. If the vehicles are driving too close to each other because of limited GPS accuracy, the vehicle controller can use information from the sensors to detect the range of nearby vehicles and control their safe positioning.

\section{Technology Details of Initial Project}

The initial Master's Research Project, dubbed AutoNet Lite, was a simplified concept demonstration of one piece of the progressive project using reduced technology and a limited communication range. The section is a brief summary of the project. The full project report is available from National University. ${ }^{12}$ The wireless technologies used included GPS, Bluetooth, and RF transmitters and receivers.

Two remote control (RC) cars communicated with a single base station, which took on the network control function. Communication between the cars and the base station was divided into an uplink and downlink, each of which employed a different wireless technology. The base station/network control function was simulated by a laptop PC running MATLAB software. The uplink, downlink and network control systems are each described in the following subsections.

\section{The Uplink}

In the uplink portion of the project, both cars constantly transmitted their updated GPS positions to the base station via a Bluetooth connection. The base station was simulated by a laptop 
equipped with a USB Bluetooth transceiver. GPS receivers mounted on top of each RC car were equipped with built-in Bluetooth transmitters.

The GPS units transmitted their current positions at the rate of one full set of coordinate readings per second through the integrated Bluetooth transmitter inside of the GPS receiver to the laptop's Class 1 Bluetooth transceiver. The network control function was simulated in the laptop using MATLAB software to continuously calculate the range between the RC cars based on the stream of coordinates transmitted from both GPS receivers. New coordinates of each car were transmitted every second from the Bluetooth GPS receivers and the new range between the cars was calculated by MATLAB and displayed on the laptop display screen once every second.

The laptop equipped with a Class 1 Bluetooth receiver and MATLAB software simulated the combination of base station and traffic network controller. It functioned as the "brain" of the network, monitoring the movement of the RC cars and "controlling" the cars by transmitting an "alert" signal" when they were in danger of colliding. The uplink devices are shown in Figure 2.
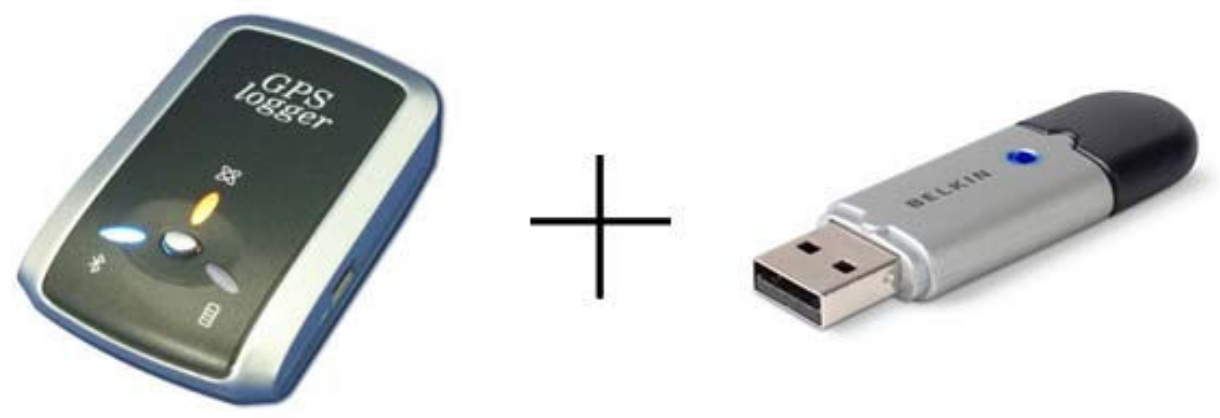

Figure 2: Devices Used for the Uplink ${ }^{13}$

\section{The Downlink System}

When the network controller detected that the range between the cars had fallen below a threshold distance, the base station sent an alert signal over the downlink. When this alert was received in the cars, a visual warning was generated by turning on LED lights and an audible warning was generated to alert the drivers. The threshold was set to allow the drivers sufficient time to slow down the cars to prevent a collision. The alert signal was sent to both cars from a FM transmitter co-located with the base-station/laptop PC to receivers mounted in the cars.

The downlink system in each car consisted of a circuit board containing a FM radio, a LED bulb, and speakers. The base station/laptop part of the downlink system consisted of a breadboard equipped master microcontroller board connected to the laptop through a serial RS-232 cable. A FM transmitter was attached to the breadboard on the microcontroller board to transmit the downlink signal. When MATLAB software in the laptop detected that the range between the cars was below threshold, it immediately signaled the master microcontroller board to transmit warning signals to the receiver boards in the cars. 


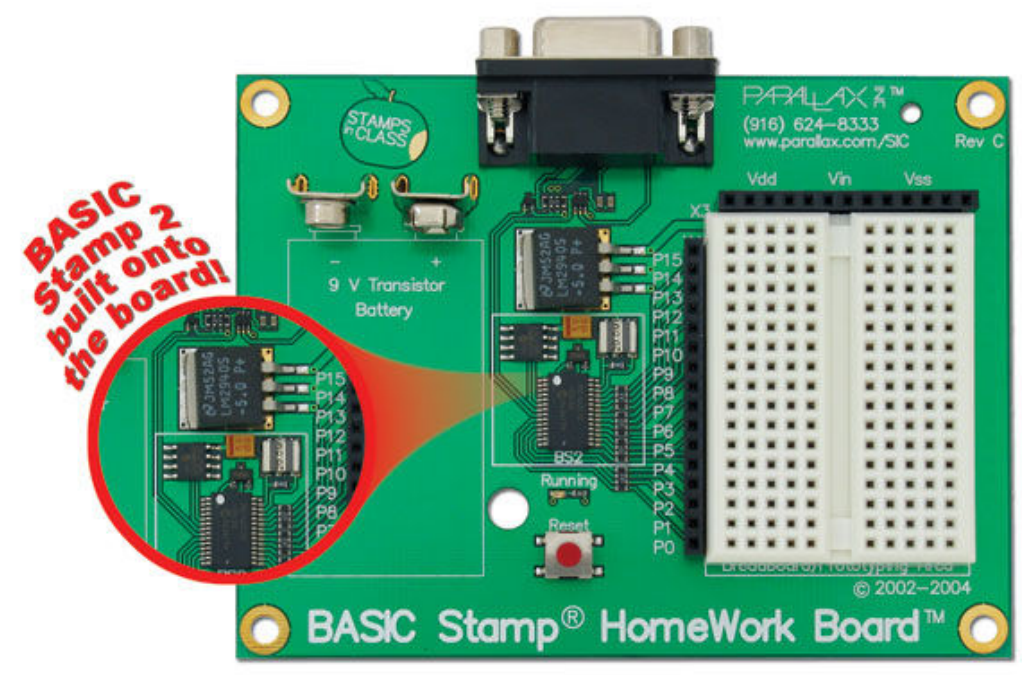

Figure 3: Laptop Part of the Downlink ${ }^{14}$

When the receivers in the cars received the warning signal sent from the microcontroller board, the breadboards in the cars generated a voltage to turn on the LED and also to activate the speakers with the audible warning.

The FM transmitter at the base station/laptop was a TWS-434 RF Transmitter equipped with a BS2 (Basic Stamp 2) microcontroller. It was connected to the laptop through a serial-to-USB adapter. Figure 3 shows the laptop PC part of the downlink system.

\section{Network Control System}

The current positions of the two GPS receivers were collected as NMEA 0183 coordinates ${ }^{15}$ in degrees, minutes, and seconds of longitude and latitude. MATLAB was used to calculate the instantaneous range between the two RC cars. The calculated range from MATLAB was found to vary from the actual measured distance by \pm 10 feet. The same program generated a continuous display of the range between the two cars as shown in Figure 4. The two color-coded dots symbolize the two RC cars, and the sequence shows the cars moving closer to each other.

\section{The Experiment}

The experiment was performed in an open field - the parking lot of National University's Spectrum Library on a Saturday afternoon to avoid objects such as parked cars that could possibly cause multipath problems.

Three possible scenarios in which collisions could occur were tested (See Figure 5):

Scenario 1 - Two RC cars were steered to head directly towards each other from 32 feet apart with a closing speed of 1 foot per second ( 0.5 foot per second for each $\mathrm{RC}$ car). 


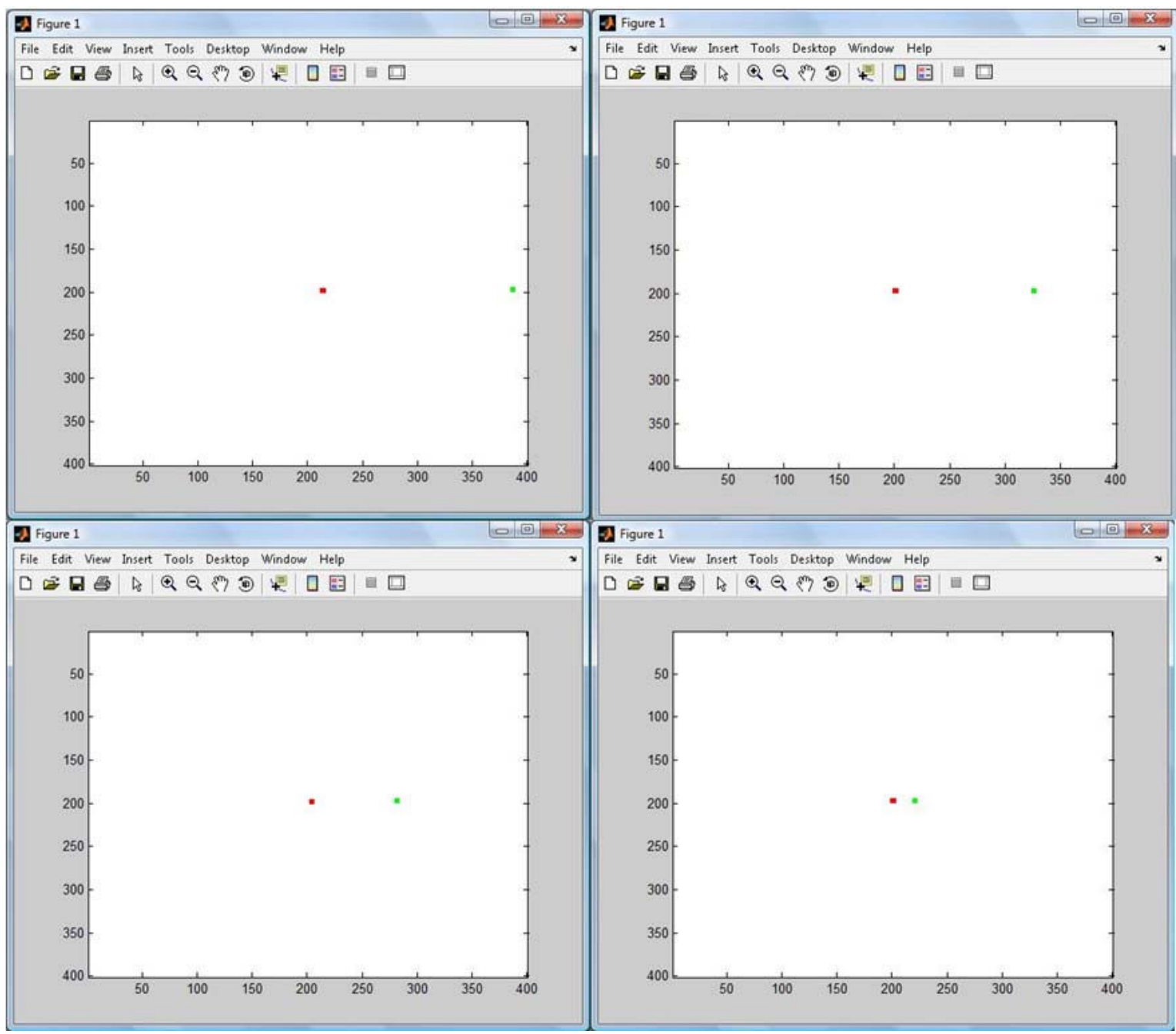

Figure 4 - Instantaneous Display of Positions

Scenario 2 - Two RC cars were steered to head towards each other on a 90-degree-angle collision-course. Once again the cars started 32 feet apart but, because they traveled at a right angle to each other, they traveled further than in Scenario 1.

Scenario 3 - Two RC cars were separated by 32 feet and both steered in the same direction but with one car going faster than the other.

The control computer calculated the range between the two RC cars and activated the warning sound and the LED lights whenever the range fell below a 15 foot threshold. Due to some GPS receiver accuracy issues, the lights and the sound turned on when the actual range between the cars averaged between 5 feet and 25 feet. Thus, the resulting range for system activation was 15 \pm 10 feet. The \pm 10 feet experimental error is consistent with the best results a civilian GPS receiver can achieve. However, real cars are not points and they have dimensions considerably larger than 10 feet. It was concluded that the actual dimensions of real automobiles could make this error unimportant for a full-scale implementation. 


\section{Conclusions of the Initial Project}

At the end of the experiments, communications were successfully established between the base station laptop and the RC cars through the uplink and downlink systems. The positions and the range between the two cars were clearly displayed, and the warning function operated satisfactorily, for this demonstration. Most importantly, the students gained a much deeper appreciation for the complexity of the engineering considerations involved in applying wireless communications to a real-world problem. As a result, their project set the stage for further research by other groups of students.

\section{Scenario 1:}

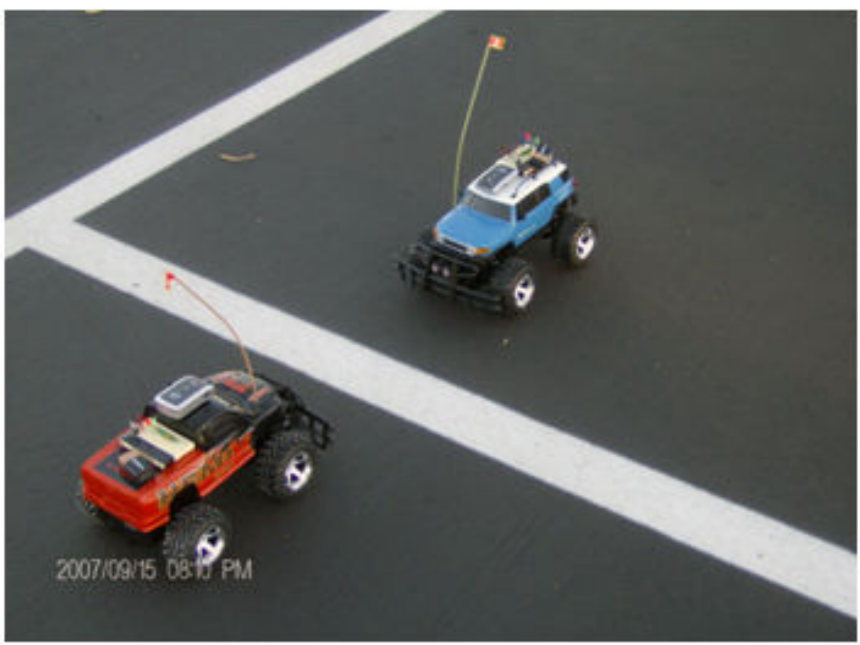

Scenario 2:

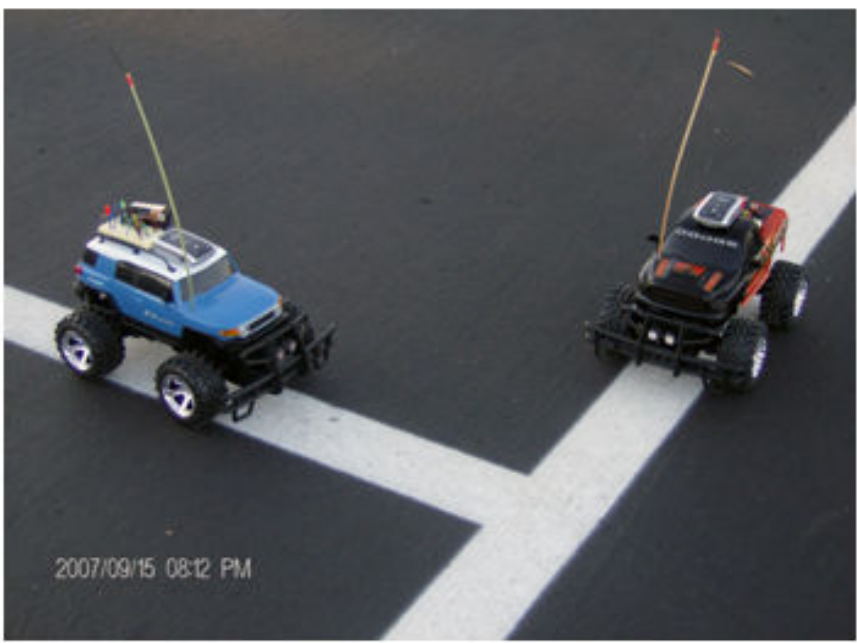

Scenario 3:

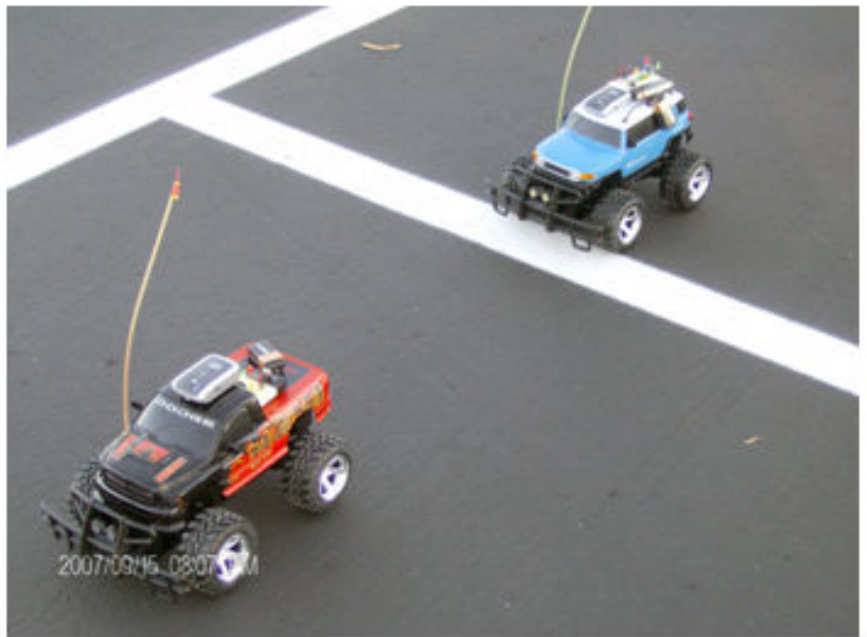

Figure 5: The Three Scenarios 


\section{Passing the Project to Future Students}

The following five-step process has been developed as the ideal for passing a "progressive project" across successive groups of students:

1. Throughout their initial project students are encouraged to identify areas they would like to have pursued if they had more time, and to incorporate their ideas for related research topics into their written results as a series of "next steps."

2. Interested faculty review student suggestions for two key characteristics:

a. One or more areas are or could be (a) suitable project(s) for other groups of students.

b. One or more areas are relevant to faculty's personal research interests and faculty is/are willing to mentor one or more groups of students to continue the research.

3. Assuming positive answers to Step \#2, the interested faculty develops a Progressive Research Project Master Plan. The Plan for a progressive research project must identify desired outcomes that can be achieved by successive groups of students in a series of 3month research projects. This should be based on the results Step \#1. Ideally this is done in conjunction with the students who completed the initial project.

4. Faculty, with students who have completed their project(s), present a Progressive Project Research Master Plan to cohorts of students who are scheduled to begin their research in the next four to six months, to stimulate interest in researching one or more of the desired outcomes identified in Step \#3.

5. Faculty allocate specific "Progressive Project" topics to research teams, based on interest.

\section{Experience with the Five-Step Process}

\section{Step \#1 - Student Identification of Future Research Areas}

The students who carried out the initial project did a good job on their project, but they were well aware that they had only touched the surface of a very complex subject. As their part of Step \#1 above, these students identified eight potential areas of research for future groups of students in the National University Master of Science in Wireless Communications program and/or in the NU Master of Science in Computer Science program.

The research areas identified, R1 through R8, were as follows:

R1. Increase GPS Accuracy - reduce the error rate from 10 feet to 3.3 feet (1 meter).

a. Purchase or build better devices.

b. Calculate more accurate differential corrections.

c. Correct firmware problems in the devices.

R2. Signal Availability - GPS and W-CDMA/WiMAX signals have to be available for the receivers at all times.

a. GPS availability in tunnels - adding repeaters inside of a tunnel for positioning estimation while cars are traveling inside tunnels. 
b. W-CDMA/WiMAX availability in tunnels - adding signal repeaters which have low multipath issues inside tunnels.

c. GPS and W-CDMA/WiMAX availability in all-terrains.

R3. The Queuing Effect (Stop and Listen before Entering Highway):

a. How should queuing be done in a network for vehicles to enter the freeway after the network acquisition?

b. How should the network adjust its capacity and traffic efficiency when a car enters the highway?

c. How should the network command the vehicle behind to react when a car enters?

R4. Network Decision-Making - since the civilian/commercial signals for the current GPS satellites update once every second, how should the network react to prevent a catastrophe if something goes wrong?

a. A vehicle traveling at 60 miles per hour travels $88 \mathrm{ft} / \mathrm{sec}$. on a highway. How should the network react if a vehicle blows a tire? Stop the cars behind? Make the cars behind change lanes and proceed at a slower speed? ...

b. The ideal distance between the vehicles should be as short as possible to enhance traffic efficiency. What is the ideal traveling distance, and how should the network adjust this range when it determines that something has gone wrong? (Note also the connection with 7a below).

R5.3D Vectors - Extend the MATLAB software to analyze NMEA 0183 streams that incorporate the $\mathrm{Z}$-vector of $\mathrm{X}, \mathrm{Y}, \mathrm{Z}$ coordinates i.e. extend the analysis to three dimensions (3D). At least two scenarios should be considered:

a. When a vehicle goes uphill/downhill and encounters another vehicle driving on a flat surface.

b. Bi-directional, double-decked highways.

R6. Terrain Modeling through EDX Software - to complement 5. above, carry out a verification of the network's 3D vector displays.

R7. Wireless Features Implementation -As envisioned, the concept will use W-CDMA and/or WiMAX wireless technology. What wireless services in addition to the basic system functions could attract consumers and advertising sponsors?

a. Wireless updating of digital maps (e.g. Google Maps).

b. Wireless internet implementation.

c. Wireless e-mail access.

d. Wireless streaming media to the vehicle (radio, video).

R8. Privacy and Security Concerns:

a. When a vehicle needs to follow a friend's car, it requires the friend's permissions before tracking. How should the system initiate this privacy acquisition? 
b. How should possible terrorism be prevented from jamming the GPS signals or hacking into the wireless network and causing a catastrophe?

c. How should wireless internet security be implemented for credit cards and personal information sent while the vehicles are on the highway?

\section{Step \#2 - Faculty Review}

The eight areas identified by the students are not exhaustive, but each area could be a good starting point for defining and conducting a good Master's Research Project. The Lead Faculty for the MSWC program reviewed the proposed areas of future research, and determined that several of them could be suitable for a three-month Masters Research project for future groups of students in the MSWC program.

\section{Step \#3 - Develop Progressive Project Master Research Plan}

Because of time limitations, Step \#3 was not completed. Instead, we moved directly to Step \#4.

\section{Step \#4 - Recruit the Next Group of Students}

In December 2007, the two alumni who completed the initial project met with a group of eight students scheduled to start their Master's Research Projects in March 2008 to introduce them to their progressive project.

\section{Step \#5 - Assign Students to Projects}

We quickly learned that we need to present progressive projects to groups of students further in advance. By three months in advance many students have already identified a research area they wish to pursue. However, we also learned that there is a second window of opportunity for "recruiting" groups of students for progressive research projects. This is during the month immediately before they are scheduled to start their research project class. As of the third week of February 2008, two students have stepped forward and requested to work on one of the R1 through R8 topics in their class beginning with March 2008.

\section{Lessons Learned}

In the future, progressive projects will be introduced earlier to students, to give them more time to consider selecting a potential subproject within a Progressive Research Project Master Plan, or to define a topic of their own that could be related to the progressive project. Students need to have completed enough of the program to understand the technologies involved in a progressive project but still have time to consider it for their own research. Six months in advance of the anticipated starting date appears to be a better time for introduction of a particular progressive project.

We believe that a Progressive Research Project Master Plan is important to "selling" future groups of students on the idea that they have an opportunity to become part of something that is important and may benefit them even after they graduate. As a result, we will place more emphasis on completing Step \#3 before presenting potential research areas to them.

We believe this approach will enable faculty to work with students to conduct more in-depth research of their own. A series of unrelated three-month Master's Research Projects does not provide enough depth for most faculty research. But, by dividing up a larger topic into threemonth segments, students can work with faculty on segments of meaningful problems. 
An important result of, our initial experience with this approach is that it has high potential for keeping the interest and engagement of alumni. Alumni are interested in the continuing work on the progressive project with which they have been involved.

We expect to make many adjustments as we learn more about how to pass progressive projects across several groups of students, but our early results are promising.

\section{Bibliography}

1 “The Engineer of 2020: Visions of Engineering in the New Century," National Academy of Engineering, (2004)

2 "National Automated Highway System Research Program - A Review", Transportation Research Board Special Report 253, National Research Council

3 "Vehicle Platooning and Automated Highways", Report of the California PATH Project, (1997)

http://www.path.berkeley. edu/ PATH/ Publications /Media/FactSheet/VPlatooning.pdf

${ }^{4}$ Peter Dizikes, "Wireless Highway”, Technology Review, March/April 2006, published by MIT

5 “Trial-Use Standard for Wireless Access in Vehicular Environments (WAVE) Resource Manager”, IEEE 1609.1, Nov 2006

6 "Trial-Use Standard for Wireless Access in Vehicular Environments - Security Services for Applications and Management Messages," IEEE 1609.2, June 2006

${ }^{7}$ Frank Kargl, "Vehicular Communications and VANET," at http://events.ccc.de/congress/2006/Fahrplan/ attachments/1216-vanet.pdf provides a good overview of VANET

${ }^{8} \mathrm{GPS}$ is a space-based radio-positioning system nominally consisting of a 24-satellite constellation that provides navigation and timing information to military and civilian users worldwide. For example, see http://www.losangeles.af.mil/library/factsheets/factsheet.asp?id=5311

${ }^{9}$ WiMAX can provide broadband wireless access up to 30 miles $(50 \mathrm{~km})$ for fixed stations, and 3 - 10 miles $(5-15$ $\mathrm{km}$ ) for mobile stations. In contrast, the Wi-Fi/802.11 wireless local area network standard is limited in most cases to only $100-300$ feet $(30-100 \mathrm{~m})$. See http://www.wimax.com/education

${ }^{10}$ Wideband Code-Division Multiple-Access (W-CDMA) is one of the main technologies for the implementation of third-generation $(3 \mathrm{G})$ cellular systems. It is based on the radio access technique proposed by the ETSI Alpha group and the specifications were finalized in 1999. See http://www.umtsworld.com/technology/wcdma.htm

${ }^{11}$ Op.Cit.

${ }^{12}$ Johnny Ken Chang and Aymen EI Salim, “The AutoNet Lite Project - The Next Generation Collision Network," submitted in partial fulfillment of the requirements for the degree of Master of Science in Wireless

Communications, National University, September 2007

${ }^{13}$ Devices Used for the Uplink. "i-Blue 747 GPS Data Logger" and "Bluetooth USB Adapter, 100 Meter". $<$ http://www.transystem.com.tw/p-gps-iblue 747.htm\#> and

$<$ http://catalog.belkin.com/IWCatProductPage.process?Product Id=273100\#> (15 Sept. 2007).

${ }^{14}$ Device Used for the Downlink. "BASIC Stamp Activity Kit."

$<$ http://www.parallax.com/detail.asp?product id $=90005>$ (15 Sept. 2007).

${ }^{15}$ The NMEA 0183 Interface Standard defines electrical signal requirements, data transmission protocol and timing, and specific sentence formats for a 4800 -baud serial data bus. 